\title{
Scolicidal activity of biosynthesized zinc oxide nanoparticles by Mentha longifolia L. leaves against Echinococcus granulosus protoscolices
}

\author{
Bushra H. Shnawa ${ }^{1,2}$ - Samir M. Hamad ${ }^{2}$. Azeez A. Barzinjy ${ }^{3,4}$. Payman A. Kareem ${ }^{5} \cdot$ Mukhtar H. Ahmed $^{6}$ (D)
}

Received: 6 May 2021 / Accepted: 3 July 2021 / Published online: 29 July 2021

(c) The Author(s) 2021

\begin{abstract}
Cystic echinococcosis is a public health problem in developing countries that practice sheep breeding extensively. In the current study, the protoscolicidal activity of biosynthesized zinc oxide nanoparticles (ZnO NPs) derived from Mentha longifolia $\mathrm{L}$. leaf extracts was investigated. The resultant $\mathrm{ZnO}$ NPs were characterized by means of various analytical techniques, such as ultraviolet-visible (UV-Vis) spectrometry, Fourier transform infrared (FT-IR) spectrophotometry, X-ray diffraction (XRD), scanning electron microscopy (SEM), and energy-dispersive X-ray spectroscopy (EDX) analysis. The results showed that the $\mathrm{ZnO}$ NP had the highest scolicidal activity at $400 \mathrm{ppm}$ concentration after $150 \mathrm{~min}$ of exposure time, showing 100\% mortality rate. The treated protoscolices exhibited loss of viability with several morphological alterations. Hence, an easy and effective green synthesis of $\mathrm{ZnO} \mathrm{NPs}$, with efficient scolicidal potential, is reported in this study.
\end{abstract}

Keywords Biosynthesis · Zinc oxide nanoparticles $\cdot$ Mentha longifolia L. S Scolicidal activity $\cdot$ Echinococcus granulosus

\section{Introduction}

Recently, biomedical nanomaterials have received more attention because of their prominent biological characteristics and biomedical applications. With the development of nanomaterials, metal oxide nanoparticles show promising and far-ranging prospect for the biomedical field, especially for antibacterial, anticancer drug/gene delivery, cell imaging, and biosensing [1]. Among these materials, zinc oxide

Mukhtar H. Ahmed

ahmed-m@email.ulster.ac.uk

1 Department of Biology, Faculty of Science, Soran University, Diana, Kurdistan, Iraq

2 Scientific Research Center, Soran University, Diana, Kurdistan Region, Iraq

3 Department of Physics, College of Education, Salahaddin University-Hawler, Erbil, Kurdistan Region, Iraq

4 Department of Physics Education, Faculty of Education, Tishk International University, Erbil, Kurdistan Region, Iraq

5 Department of Food Technology, Agricultural Engineering, Salahaddin University-Hawler, Erbil, Kurdistan Region, Iraq

6 Sisaf Drug Delivery Nanotechnology, Ulster University, JordanstownBelfast BT37 0QB, UK
$(\mathrm{ZnO})$ nanoparticle is considered a good candidate in biocompatible application due to its biocompatibility, economic advantage, and low toxicity $[1,2]$. Several methods such as physical [3], chemical [4], and biological methods [5] are used to synthesize ZnO NPs. The physical methods require high pressure and high temperature which are rather expensive [6]. On the other hand, the chemical methods have a harmful impact due to the utilization of chemical materials as reducing agents, which causes many issues for the users and the ecological system [7, 8].

In fact, biological substances such as plant extracts, fungi, and bacteria are used for the synthesis of nanomaterials and they have many benefits for biomedical applications [9] Among these biological sources for creating the nanostructures, plants have a significant role as a result of presence of large number of phytochemicals such as flavonoids, glycosides, polyphenol, terpenoids, and enzymes [10].

It can be stated that the main difference between biosynthesis and other methods for nanoparticle preparation is that, first, the nanoparticles will be reduced, capped, and stabilized by phytochemicals which are available in the plant extract. Second, these phytochemicals are nontoxic, low-cost, and environmentally friendly and can be done within one pot [11]. Third, even after separation and purification stages of NP preparation, there are some $\mathrm{OH}$ and 
other functional groups remaining to bind with the nanoparticles which make the nanomaterials more reactive than the other methods. For instance, the chemical method is not environmentally friendly and some of the reduction chemical materials are extremely toxic; i.e., they have harmful impact on the human life and environment, and most of them are expensive. Accordingly, researchers have paid more attention to the biological method for synthesizing metal and metal oxide NPs.

The use of nanoparticles has been disseminated for medical applications as a result of their important and unique features, for example, surface to mass ratio that is much larger than that of other particles, and their quantum properties and abilities to adsorb and carry other materials like drugs, probes, and protein [12]. This study is our continuing investigation in the green synthesis nanoparticle area [5, 13-19].

Spillage of hydatid fluid rich in viable protoscoleces is the leading cause of echinococcosis recurrence; therefore, scolicidal agents are used for inactivating the protoscoleces during surgical procedure. However, these materials have adverse impacts totally [20]. Hypertonic saline is applied as a protoscolicidal material nowadays. Still, it caused hypernatremia, which results in convulsions, intracranial hemorrhage, necrosis and degeneration, and myelinolysis [21, 22].

Cystic echinococcosis (CE) is a neglected zoonotic parasitic disease caused by the larval stage of the cestode Echinococcus granulosus and transmitted to humans by dogs [23]. Several studies have considered the disease as emerging and re-emerging with an increasing medical and public health concern in many countries [24]. Echinococcal infection has been designated by the World Health Organization as a neglected tropical disease because it principally affects economically poor populations in medically underserviced locations [25]. In Iraq, the disease is categorized as hyper endemic and it is one of the country's most significant parasitic infections with major socio-economic consequences, due to its effect on both humans and livestock [26]. Findings in other research confirmed the high prevalence of CE in North Africa and the Middle East [27]. It is a life-threatening disease and complicated to treat; treatment of CE can only be achieved by surgical removal of the hydatid cyst in combination with anti-parasitic chemotherapy, and in some cases the disease inactivation of the protoscoleces by the method called PAIR (punctuation, aspiration, injection, reaspiration), combined with chemotherapy [28]. Despite the progress in surgical technique, secondary infection, resulting from spillage of viable protoscoleces during the intervention, may occur. Prevalence of recurrence was recorded in $2-25 \%$ of cases [29]. Additionally, anaphylactic reactions present a further risk; therefore, protoscolices are habitually applied, because of the risk of spillage of cyst fluid [30]. Treatment of CE still relies upon benzimidazole, like albendazole and mebendazole, which targets parasite $\beta$-tubulin, consequently preventing the formation of microtubules; this leads to the destruction of the cell structure and subsequent death of the parasite [31]. However, due to the similarity between mammalian and parasite $\beta$-tubulin ( $>90 \%$ identical amino acid residues), benzimidazoles exhibited severe adverse side effects like leukopenia, alopecia, hepatotoxicity, and thrombocytopenia [32]. Moreover, prolonged drug therapy, following the infection, is recommend. In addition, usage of benzimidazole is mainly limited due to its low aqueous solubility and poor bioavailability. Therefore, poor gastrointestinal absorption results in inadequate systemic availability and lowered efficacy against hydatid disease [33]. Consequently, there is a constant motivation toward exploring a promising alternative to prevent the recurrence rate of the infection and to overcome the side effects of synthetic medication [34].

Several researchers investigated the anti-parasitic and inhibitory effects of several nanoparticles on protoscolices. For example, Moazeni et al. found out that the combination of povidone iodine and silver nitrate, and Eucalyptus globulus essential oil showed a potent natural scolicidal agent [35]. Also, Salih and his group revealed that silver nanoparticles (Ag NPs,) which were synthesized using Eucalyptus globulus, have powered scolicidal of $47.8 \%$ after $45 \mathrm{~min}$ of incubation [36]. Barabadi et al. showed that gold nanoparticles (AuNPs) obtained through green synthesis have high scolicidal effects [37]. In view of the above facts, the aim of the current study was to investigate the efficacy of biosynthesized $\mathrm{ZnO}$ NPs using leaf extract of Mentha longifolia L. as scolicidal agent against protoscolices of E. granulosus within the in vitro model.

\section{Materials and methods}

In this work, the double distilled water has been used for growth and treatments processes. All the utilized chemical materials such as zinc nitrate hexahydrate, $\mathrm{Zn}\left(\mathrm{NO}_{3}\right)_{2} \cdot 6 \mathrm{H}_{2} \mathrm{O}$, sodium hydroxide, $\mathrm{NaOH}$, and eosin stain are purchased from Sigma-Aldrich without further purifications.

\subsection{Plant collection}

Fresh and healthy leaves of Mentha longifolia L. were collected from Shaqlawa city $\left(36^{\circ} 24^{\prime} 20^{\prime \prime} \mathrm{N}, 4^{\circ} 19^{\prime} 15^{\prime \prime} \mathrm{E}\right)$ in the Erbil Governorate in the Kurdistan Region of Iraq.

\subsection{Synthesis of $\mathrm{ZnO}$ nanoparticles}

Twenty-five grams of fresh seasonable Mentha longifolia L. leaves was washed and cut into small pieces, and then heated in $250 \mathrm{~mL}$ double distilled water for $40 \mathrm{~min}$ at $80^{\circ} \mathrm{C}$. The aqueous extract was then filtered and kept in refrigerator for 
further steps of the study. After this, the remainders were filtrated by using Whatman No.1 filter paper. For the preparation of the $\mathrm{ZnO}$ NPs, pure extraction was utilized to make an aqueous solution. A total of $50 \mathrm{~mL}$ of Mentha longifolia L. leaves extracted was added drop wise to $50 \mathrm{~mL}$ of zinc nitrate $\left[\mathrm{Zn}\left(\mathrm{NO}_{3}\right)_{2}\right]$, under magnetic stirring at $75{ }^{\circ} \mathrm{C}$ for $40 \mathrm{~min}$. In addition to that, the $\mathrm{pH}$ of the final solution was handled by adding $1 \mathrm{M}$ sodium hydroxide $(\mathrm{NaOH})$ until a color change was observed in the final mixture, signifying the nucleation of ZnO NPs, as checked by UV-Vis method, followed by formation of some snowy sedimentation. The interaction of plant phytochemicals with metal salts alters the color of the reaction mixture and this is an indication of nanostructure formation which can be detected by means of Super Aquarius Cecil CE9500 UV/VIS dual beam spectroscopy. Indeed, this method effortlessly proves the formation of nanostructure as it is a thumbprint technique and, in this case, the green synthesized nanoparticles display their surface plasmon resonance (SPR). Thus, the brownish colored solution indicates the formation of $\mathrm{ZnO}$ nanoparticles.

The sedimentation was totally separated by using centrifugation at $7000 \mathrm{rpm}$ for $30 \mathrm{~min}$ and the solid powder was cleaned with methanol and distilled water four times to remove possible contaminating and other organic materials. Lastly, part annealing followed out on the Bunsen burner flame at $\sim 500{ }^{\circ} \mathrm{C}$ for $\sim 1 \mathrm{~h}$ as shown in Fig. 1 .

\subsection{Characterization techniques}

X-ray diffraction measurements were carried out using a PAN analytical X' Pert PRO $(\mathrm{Cu} \mathrm{K} \alpha=1.5406 \AA)$. The scanning rate was $1^{\circ} / \mathrm{min}$ in the $2 \theta$ range from 20 to $80^{\circ}$. A UV-Vis double-beam spectrophotometer (Super Aquarius) was used to monitor the formation of $\mathrm{ZnO}$ NPs. Also, morphology study was investigated by field emission scanning electron microscopy (FESEM) (Quanta 4500). The chemical composition of the prepared nanostructures was measured by EDX (energy-dispersive X-ray spectroscopy) performed in FESEM.

\subsection{Collection of protoscolices and viability test}

Hydatid cysts of $E$. granulosus were obtained from naturally infected liver of sheep from the Department of the Veterinary Medicine in Soran city, Kurdistan region in Iraq.

In accordance with Evrard et al. [33], the hydatid fluid was aseptically collected from the cyst. The collected fluid with protoscolices was transferred to a glass beaker and left for $15 \mathrm{~min}$ to allow the protoscolices to settle down. After that, the supernatant was discarded, and the precipitated protoscolices were washed with normal saline. The viability of protoscolices was assessed by their motility under light microscopy. In addition, the viability was also detected by using $0.1 \%$ aqueous eosin stain. After exposure for $5 \mathrm{~min}$ to the stain, unstained protoscolices were considered viable, whereas stained protoscolices were recorded as dead. When $97 \%$ or more viable protoscolices were present in the sediments, the sample was appropriate for the experiments.
Fig. 1 Schematic diagram of green synthesized $\mathrm{ZnO}$ nanoparticles

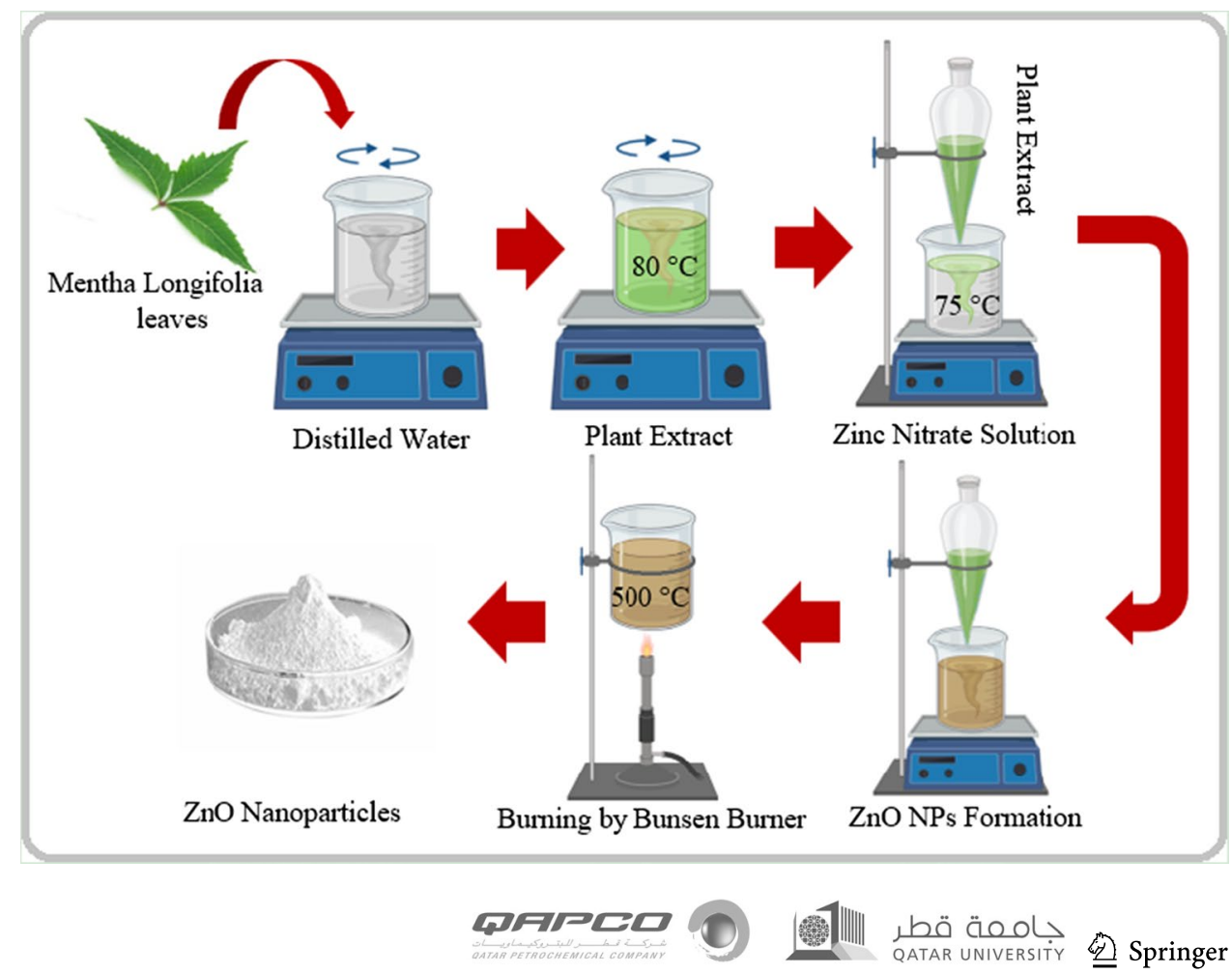




\subsection{In vitro scolicidal effect of ZnO NPs}

To investigate the scolicidal effect of ZnO NPs against protoscolices of $E$. granulosus, stock solution for the nanoparticles was prepared and different concentrations of $400 \mathrm{ppm}$, $200 \mathrm{ppm}$, and $100 \mathrm{ppm}$ were prepared to test against the parasite with different exposures ( $15 \mathrm{~min}, 30 \mathrm{~min}, 1 \mathrm{~h}, 1.5 \mathrm{~h}$, $2 \mathrm{~h}$, and $2.5 \mathrm{~h}$ ). Aliquot of $1 \mathrm{~mL}$ of each concentration was placed in each test tube to which approximately 10,000 protoscolices were added. The contents of the test tubes were mixed well and incubated at room temperature. At the end of each incubation period, the supernatant was discarded gently; $1 \mathrm{~mL}$ of $0.1 \%$ eosin stain was added to the settled protoscolices. After $5 \mathrm{~min}$, the upper part of the solution was again removed. The protoscolices were put on glass slide and covered with a cover slip and examined for viability by light microscopy. The percentage of mortality was determined by counting at least 100 protoscolices and estimated as percentage. Non-treated protoscolices with $\mathrm{ZnO}$ NPs which were kept in normal saline was considered the control for each incubation time. Each test was performed in triplicate.

\section{Results and discussion}

\subsection{UV-Vis analysis}

The optical property of ZnO NPs was investigated using ultraviolet and visible absorption spectroscopy. UV-Vis spectroscopy is usually used to confirm the synthesis of $\mathrm{ZnO}$ NPs. Conducting electrons vibrate at a certain wavelength range and this is due to the surface plasmon resonance (SPR) effect. Figure 2 shows the UV-Vis spectra for the synthesized $\mathrm{ZnO}$ NPs. An absorption band centered at

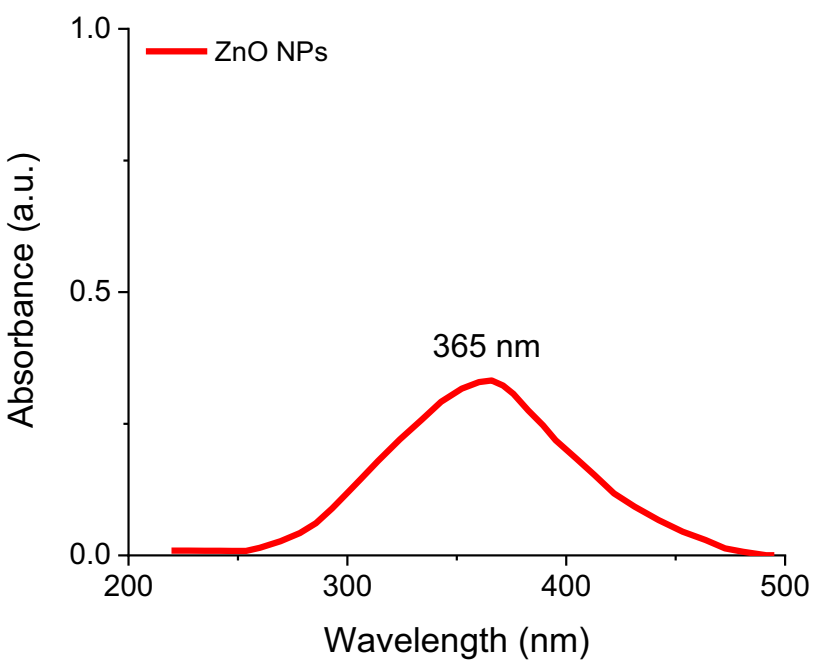

Fig. $2 \mathrm{UV}-\mathrm{Vis}$ spectrum of $\mathrm{ZnO}$ nanoparticles

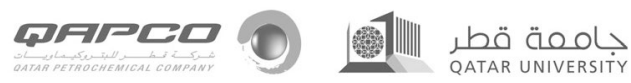

$365 \mathrm{~nm}$ proves the existence of $\mathrm{ZnO}$ NPs in the solution. The obtained UV-Vis results showed there is not any absorption peak around $500 \mathrm{~nm}$, which indicates that $\mathrm{ZnO}$ nanoparticles are free of ionized oxygen (hydroxyl free). Also, the outcome result is in a very good agreement with previously reported works [38-40].

\subsection{XRD analysis}

The XRD diffraction peaks of the green synthesized $\mathrm{ZnO}$ NPs are shown in Fig. 3. The XRD patterns illustrate the peaks of the $\mathrm{ZnO}$ NPs at $31.90^{\circ}, 34.57^{\circ}, 36.41^{\circ}, 47.70^{\circ}$, $56.76^{\circ}, 62.97^{\circ}, 66.58^{\circ}, 68.07^{\circ}, 69.21^{\circ}, 72.75^{\circ}, 76.98^{\circ}$, and $81.51^{\circ}$, which matches with the lattice parameters of $(10$ 0), (0 $\left.\begin{array}{ll}0 & 2\end{array}\right),\left(\begin{array}{lll}1 & 0 & 1\end{array}\right),\left(\begin{array}{lll}0 & 1 & 2\end{array}\right),\left(\begin{array}{lll}1 & 1 & 0\end{array}\right),\left(\begin{array}{lll}0 & 1 & 3\end{array}\right),\left(\begin{array}{lll}2 & 0 & 0\end{array}\right),\left(\begin{array}{lll}1 & 1 & 2\end{array}\right)$, ( $\left.\begin{array}{lll}2 & 0 & 1\end{array}\right),\left(\begin{array}{lll}0 & 0 & 4\end{array}\right)$, and (2 02 2), respectively. These planes can be indexed to the hexagonal wurtzite structure of the sample based on the International Center of Diffraction Data card (JCPDS-36-1451). Moreover, the lack of other peaks and signals indicates the phase purity of green synthesized $\mathrm{ZnO}$ NPs. Finally, the obtained XRD result of $\mathrm{ZnO}$ nanoparticles is in good agreement with those reported from previous literatures [41-43].

The lattice constants of the $\mathrm{ZnO}$ sample were determined at room temperature experimentally; from the XRD results, the lattice constant (a) parameter is $3.2346 \AA$ and the (c) is $5.2120 \AA$ for the NPs. The narrow and strong diffraction

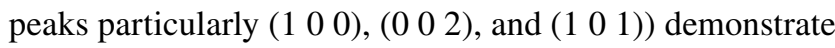
the high crystalline quality of the $\mathrm{ZnO}$ sample. Through the XRD analysis data, the estimated size of the ZnO NPs was obtained using Debye-Scherrer's formula given by the following equation:

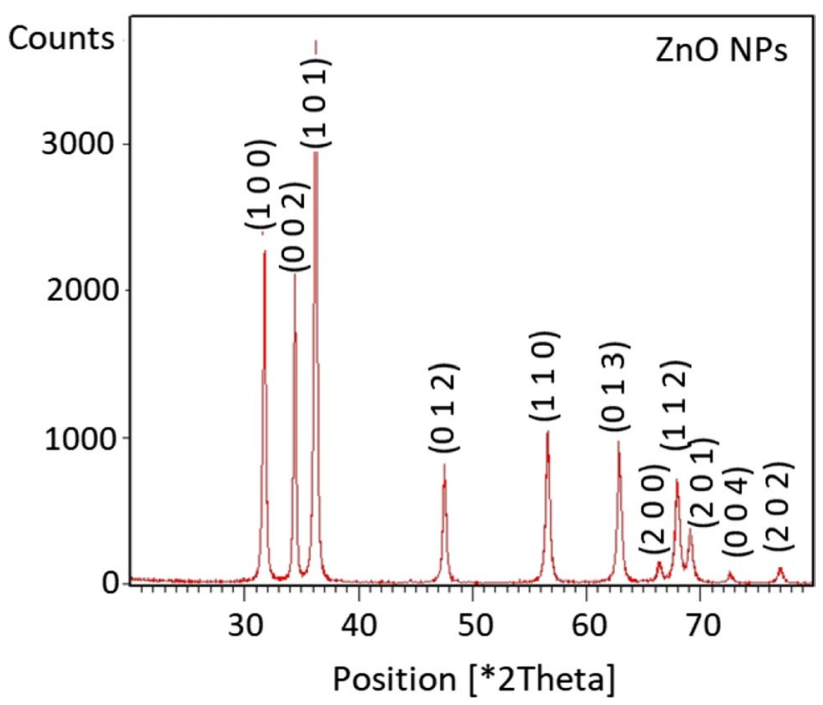

Fig. $3 \mathrm{XRD}$ result for the synthesized $\mathrm{ZnO}$ nanoparticles by zinc nitrate and Mentha longifolia L. extract 
$D=\frac{0.94}{\beta \cos \theta}$

where $D$ is the crystalline size, $\lambda$ is the $\mathrm{X}$-ray wavelength, equals to $1.5406 \AA$, and $\beta$ is the full width half maximum (FWHM) of the dominant peak (1 01$)$, 0.003. Therefore, the average crystalline size of the $\mathrm{ZnO}$ nanoparticles can be calculated to be in the range of 60-70 nm. Similar results have been obtained by both Wang et al. and Dash et al. [44, 45].

\subsection{SEM and EDX analysis}

The SEM analysis is conducted to investigate the morphology of the $\mathrm{ZnO}$ nanoparticle. Here, a FESEM scanning electron microscope is used to demonstrate the shape and the size of ZnO NPs as shown in Fig. 4. From the SEM image, the random distribution of the agglomeration of smaller NPs with the presence of spherical shaped nanoparticle is clearly shown and the average particle size is comparable with our calculation from Debye-Scherrer's equation using XRD results.

To obtain additional insight into the topographies of $\mathrm{ZnO}$ nanoparticles, the EDX analysis of the sample was performed from the same area as shown in Fig. 5. The EDX analysis confirms the presence of zinc oxide nanoparticles grown by the biosynthesized method. The elemental analysis of the ZnO NPs yielded $\sim 78.5 \%$ of zinc and $21.5 \%$ of oxygen which proves that the produced $\mathrm{ZnO} \mathrm{NP}$ is in its highest purified form [46]. The main components of the $\mathrm{ZnO}$ sample are $\mathrm{Zn}$ and $\mathrm{O}$ content, and also, they are uniformly dispersed on the surface of $\mathrm{ZnO}$ nanoparticles. The EDX study assured the existence of the zinc and oxygen and the presence of Au in EDX analysis is as a result of using gold coating in order to get better SEM images. From the X-ray diffraction peaks, SEM micrographs, and EDX results, one can show that high-quality $\mathrm{ZnO}$ nanoparticles were formed without any impurity or other secondary phases.

\subsection{FT-IR analysis}

FT-IR analysis was implemented to verify the pureness and nature of the biosynthesized ZnO NPs. Metal oxides, in general, offer absorption bands in the fingerprint region, i.e., below $1000 \mathrm{~cm}^{-1}$ rising from interatomic vibrations. Therefore, in order to assess the composition and structural quality of the ZnO NPs, an FT-IR spectrophotometer should be utilized. Additionally, the FT-IR spectrum provides information on the type of bonding within the samples in all phases of matter [47].
The FT-IR spectra of the powder samples of the biosynthesized $\mathrm{ZnO}$ NPs are presented in Fig. 6. Firstly, the narrow absorption peak at around $3455 \mathrm{~cm}^{-1}$ is attributed to the $\mathrm{O}-\mathrm{H}$ stretching vibration of the intermolecular hydrogen bond. The appearance of this peak is probably due to the atmospheric moisture. The peak around $1362 \mathrm{~cm}^{-1}$ corresponded to the amine $(\mathrm{N}-\mathrm{H})$ group of proteins or enzymes that exist in the utilized plant extract. The peak around $1115 \mathrm{~cm}^{-1}$ attributed to $(\mathrm{C}-\mathrm{O})$ bond, while the peak around $872 \mathrm{~cm}^{-1}$ is more likely corresponding to phenolic groups which are available in the plant extract [48]. The absorption peak at around $872 \mathrm{~cm}^{-1}$ is as a result of the formation of tetrahedral-coordination of zinc [49]. The sharp peak between 444 and $519 \mathrm{~cm}^{-1}$ is attributed to the $\mathrm{ZnO}$ stretching bonds. Similar results have been found by other researchers [50-52].

\subsection{Scolicidal efficiency of ZnO NPs}

The results of the present study indicated the powerful in vitro scolicidal efficiency of the biosynthesized $\mathrm{ZnO}$ NPs. Figure 7 shows the percentage of mortality within the protoscoleces of E. granulosus which were treated with different concentrations of ZnO NPs (100 ppm, 200 ppm, and $400 \mathrm{ppm}$ ) in comparison to the untreated ones, i.e., control protoscoleces. The maximum protoscolicidal effect was found at a concentration of $400 \mathrm{ppm}$, followed by $200 \mathrm{ppm}$ and $100 \mathrm{ppm}$. The viability test was done for the protoscoleces sample and observed as $97 \%$ and considered appropriate to use in the experiment. The same sample was used for control and treatment, depending on the references.

In protoscoleces incubated with $400 \mathrm{ppm}$, the percentage of mortality reached $90 \%$ and $100 \%$ following 2.0 and $2.5 \mathrm{~h}$ of incubation, respectively. Also, all protoscoleces absorbed the eosin stain and colored red which indicated their death within $2.5 \mathrm{~h}$ after incubation, whereas the protoscoleces of the control group remain viable and seemed to be colorless. These results demonstrate the dose-dependent protoscolicidal effect of ZnO NPs on E. granulosus protoscoleces. Similar outcomes have been found by Norouzi et al. [53, 54].

On the other hand, the mortality rate was low, by increasing the time of exposure and decreasing concentration. As shown in Fig. 7, after $2.5 \mathrm{~h}$ of incubation, the mortality percentages were $100 \%, 69 \%$, and $62 \%$ at 400,200 , and $100 \mathrm{ppm}$ of $\mathrm{ZnO}$ NPs, respectively, which indicated that the mortality percentage was time-dependent also, because the protoscolicidal efficacy of $\mathrm{ZnO}$ NPs increased on exposure for longer time periods [55].

There are several cardinal factors that influence the activities of nanoparticles that have been synthesized using green technology, the factors like particle size, pore size, shape, structure properties, and chemical composition. These

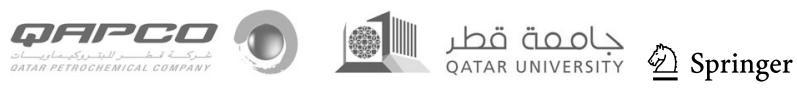


factors are directly related to the synthesis parameters of nanoparticles such as $\mathrm{pH}$ of the solution, temperature, concentration of the extracts used, concentration of the raw materials used, size, and above all the protocols that are followed for the synthesis process $[56,57]$.

\subsection{Morphological effects of ZnO NPs on $E$. granulosus protoscolices}

The current study revealed that some protoscolices after incubation with $\mathrm{ZnO}$ NPs absorbed the eosin stain and colored red which indicated their death (Fig. 8b). Tegument of the parasite is the first part that got affected (Fig. 8f); most of the protoscolices were invaginated and showed different alterations like tegumental damage, disorganization of rostellar hooks, and loss of calcareous corpuscles (Fig. 8e, i). In addition, Fig. 8c showed evaginated protoscolex which partially absorbed the eosin stain that indicate the initiation of its death [54]. The present finding showed that no viable protoscolices were noticed after $2.5 \mathrm{~h}$ of incubation with $\mathrm{ZnO}$ NPs at concentration of 400 ppm as in Fig. 8g.

On the other hand, the protoscolices of the control group seemed to be colorless and viable during the period of experiment and seemed to be morphologically intact with clear and bright calcareous corpuscles (Fig. 8d).

Up to now, the preferable method for hydatid disease treatment is surgery [58]; however, spillage of hydatid fluid rich in protoscolices during surgical operation is the main cause of its recurrence as it forms secondary infection, in addition to the anaphylactic reaction which may lead to patient death [59]. Therefore, the injection of the cyst with protoscolicidal agents is an integral part of the surgery.

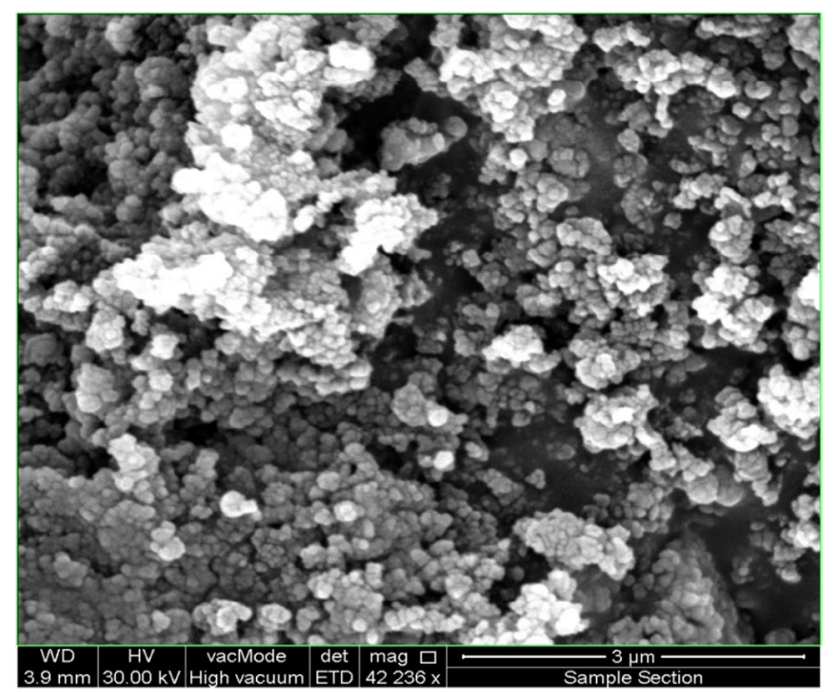

Fig. 4 FESEM micrographs of green synthesized $\mathrm{ZnO}$ nanoparticles

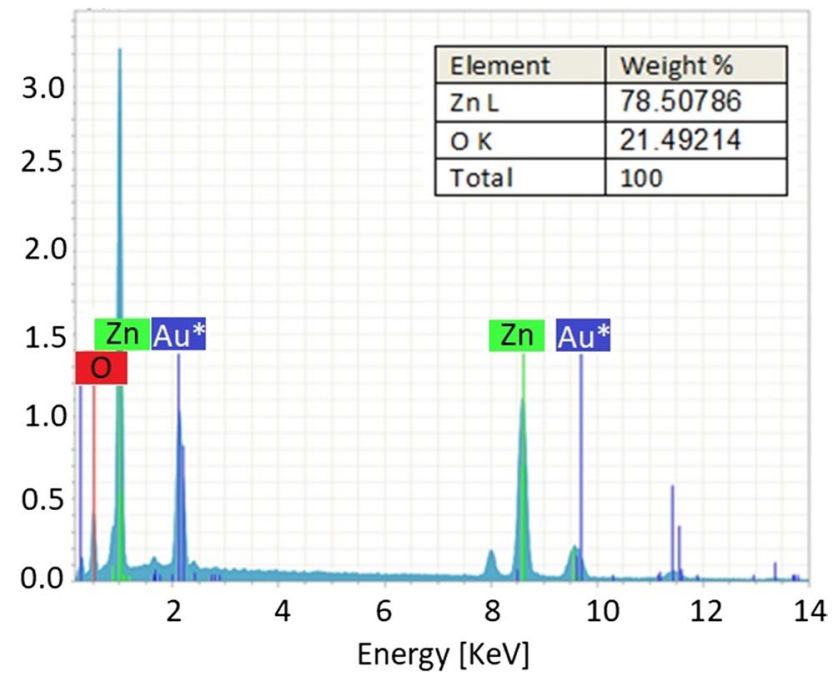

Fig. 5 EDX analysis of $\mathrm{ZnO}$ nanoparticles

There has been no record of an effective and safe agent yet. So, the exploration of new and effective scolicidal material with minimal side effect is highly recommended for urgent demand [37].

The findings of the present study showed that the $\mathrm{ZnO}$ NPs exhibited potential scolicidal effect which is timedependent [60]. This effect may be contributed to the characteristics of NPs, the role of which against bacteria has been explained above, like their high surface area-to-volume ratios.

There are two proposed mechanisms for the explanation of the interaction between NPs and bacteria, mostly attributed to extreme reactive oxygen species (ROS) generation, mainly hydroxyl radicals and singlet oxygen [61], and the precipitation of NPs on the bacterial surfaces; or NPs accumulate in the cytoplasmic area or in the periplasmic space, and hence disrupt the cellular activities, leading to membrane disturbance, reasons of some of the effect by direct liaison between the NPs and the membrane in addition to ROS generation close to the bacterial membrane [62]. Sirelkhatim et al. suggested a formation of electrostatic forces during treatment of $E$. coli with $\mathrm{ZnO}$ [63]. Other researchers also explained these electrostatic relations between NPs and bacteria cell surfaces as a source for growth inhibition, and that the total bacterial charge is negative, owing to the extreme production of carboxyl groups [64, 65]. Therefore, the cell membrane is negatively charged; ZnO NPs possess a positive charge in a water suspension [66]. These reverse charges increase the whole effect by generating electrostatic forces, which act as a strong bond between NPs and the membrane of the microbes. Consequently, the bacterial membrane is damaged. 
Fig. 6 FT-IR spectra of the biosynthesized ZnO NPs from Mentha Longifolia L. leaf extracts and zinc nitrate salt

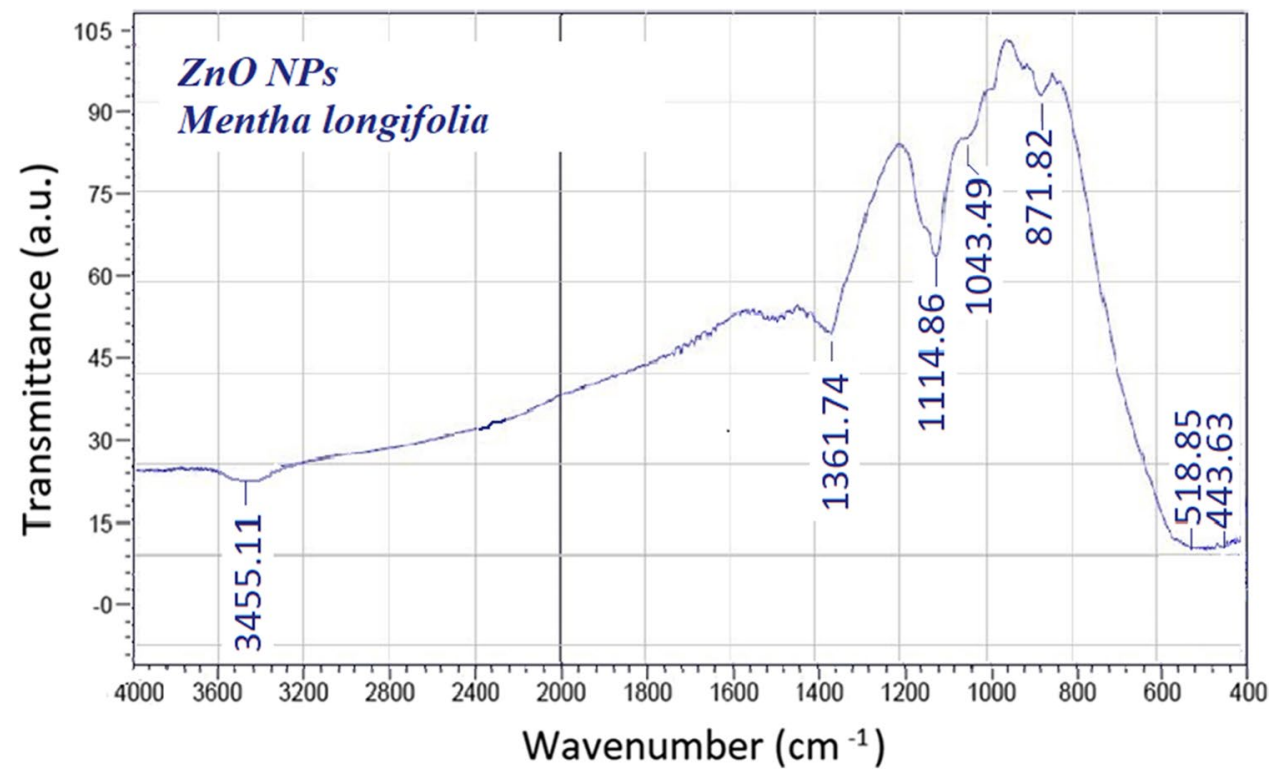

Recently, the same fact was documented regarding $\mathrm{ZnO}$ NPs; Ishida and coworkers concluded that the antibacterial effects are as a result of cell wall damage by $\mathrm{ZnO} O$-localized reaction, which leads to increase permeability of the membrane, NP internalization because of uptake of toxic zinc ions, and ROS creation [67].

Furthermore, the results of the current study pointed out that the tegument of the parasite was the primary site of destruction when treated with $\mathrm{ZnO}$ NPs, which finally results in death. Tegument plays a vital role in the physiology of the cestode owing to its role in nutrition absorption, defense against enzymatic and immunological attack of the host, excretion, and ionic exchange [68]. Moreover, the alteration in the tegument affects the tegumental microtriches which interfere with protoscolices' nutrition [69]. The death of the

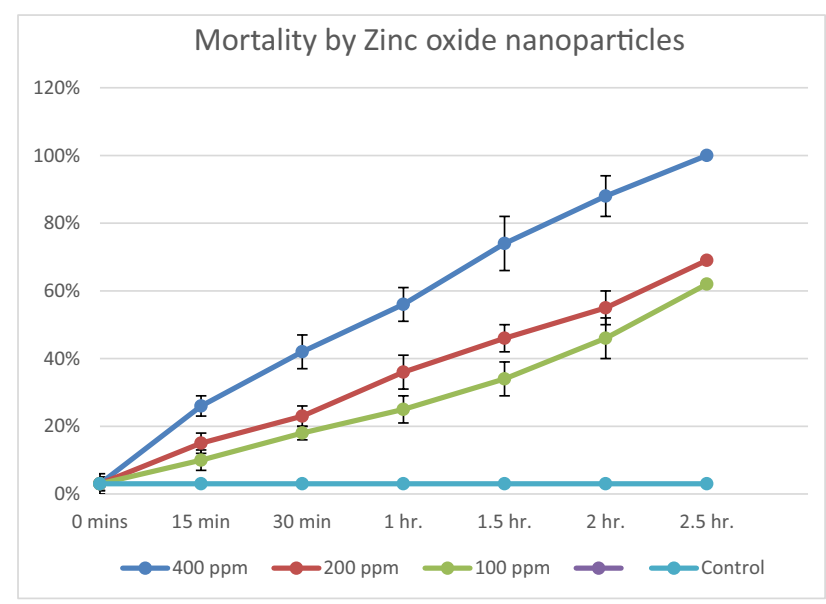

Fig. 7 Scolicidal effect of ZnO NPs against protoscolices of E. granulosus parasite may be due to programmed cell death or apoptosis which is the common type of eukaryotic cell death [70]. Furthermore, high level of apoptosis has been mentioned in Cystic echinococcosis of E. granulosus [71].

Mahmoudvand et al. have concluded that biogenic Se NPs which were synthesized by Bacillus have potent scolicidal effects particularly at concentrations 500 and $250 \mu \mathrm{g} / \mathrm{mL}$ as $100 \%$ mortality after 10 and $20 \mathrm{~min}$ of treatment, respectively [72]. Additionally, Rahimi et al. conducted a study on the effects of biosynthesized silver NPs which were derived from Penicillium aculeatum against protoscoleces [73]. Their findings pointed out that Ag NPs had effective and promising scolicidal action. Moreover, they recommended that Ag NPs can be considered potent scolicidal agent and could be applied for biomedical applications, due to their is cost-effectiveness and safety as they need nontoxic materials in comparison with the chemical process [73].

Furthermore, Barabadi et al. indicated that the green synthesized gold NPs from Penicillium aculeatum revealed scolicidal efficacy against protoscolices of E. granulosus [55]. High percentage of mortality was documented in the protoscolices which were treated with $0.3 \mathrm{mg} / \mathrm{mL}$ AuNPs for $120 \mathrm{~min}$. The results of the Barabadi et al. study showed that AuNPs could be considered probable anti-E. granulosus agent. They explained the anti-parasitic activity of the abovementioned nanoparticles by their high surface areato-volume ratio, which leads to new mechanical, chemical, electrical, optical, magnetic, electro-optical, and magnetooptical properties which are unlike their original characteristic [37].

Similarly, Ashajyothi et al. investigated the toxicity of biosynthesized ZnO NPs by a couple of administration routes (intra-peritoneal and intravenous) into experimental

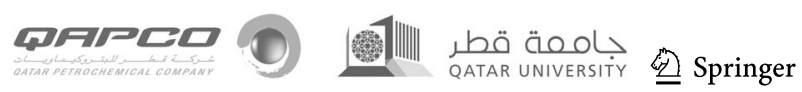



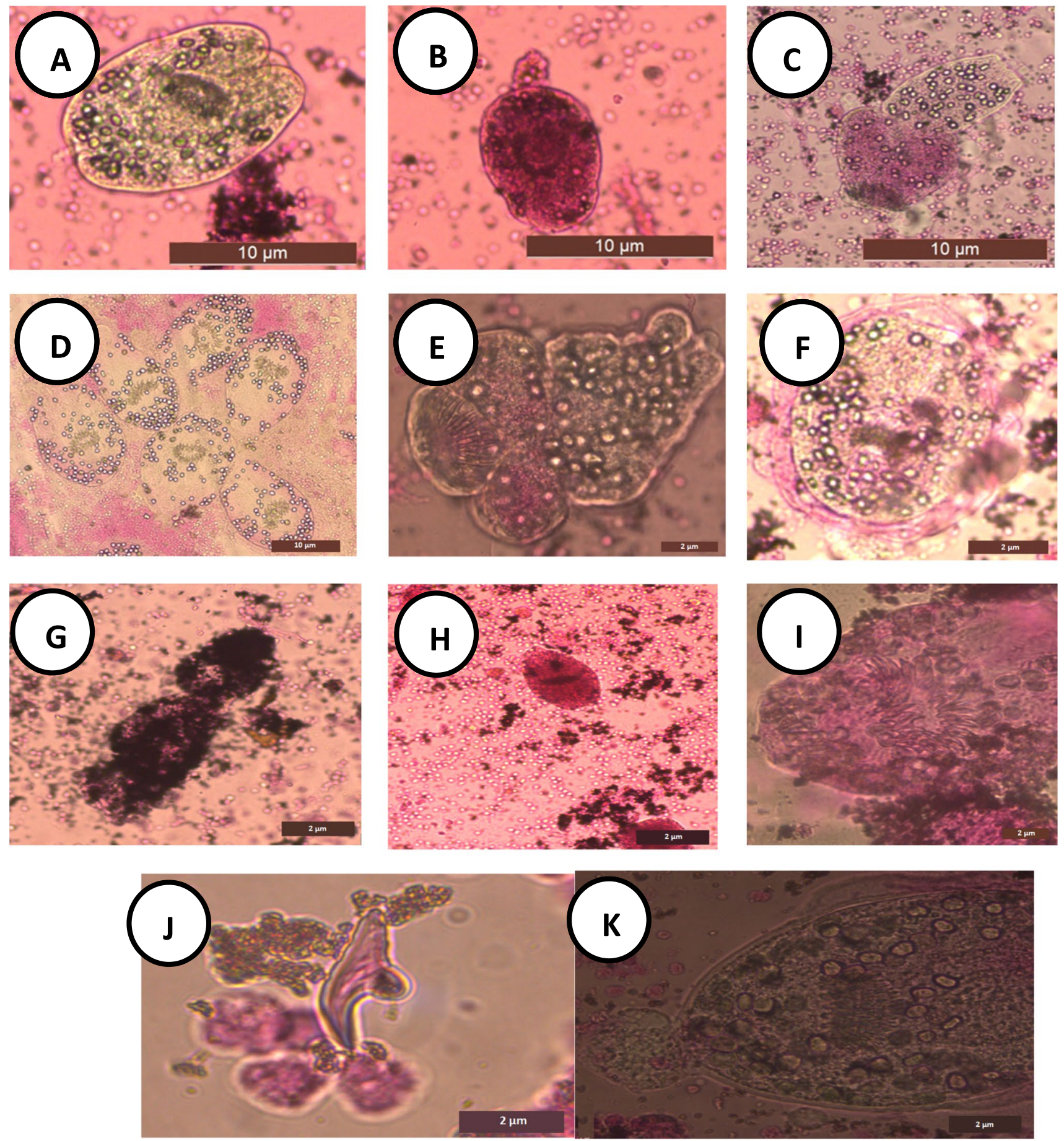

Fig. 8 Representative images from light microscopy. a Alive protoscolex after staining with $0.1 \%$ eosin stain. b Dead protoscolex after treatment with $\mathrm{ZnO}$ NPs after $30 \mathrm{~min}$ of exposure to $\mathrm{ZnO}$ NPs. c Partially dead evaginated protoscolex after $30 \mathrm{~min}$ of exposure to $\mathrm{ZnO}$ NPs. d Alive protoscolices without exposure to ZnO NPs and after staining with eosin. e Evaginated protoscolex showed altered tegument after 90 min of exposure to ZnO NPs. f Dead protoscolex showed tegumental damage after 90 min of incubation with $\mathrm{ZnO}$ NPs. $g$ Totally dead and damage protoscolices after $2 \mathrm{~h}$ of incubation with ZnO NPs. $\mathbf{h}$ Two dead protoscolices after $30 \mathrm{~min}$ of exposure to ZnO NPs. i Dead protoscolex with rostellum disorganization. j Hook of damaged protoscolex. $\mathbf{k}$ Altered protoscolex after $1 \mathrm{~h}$ of exposure to $\mathrm{ZnO}$ NPs 
rats [74]. Their findings revealed that bio-ZnO NPs have no effects on the organs of the treated animals in comparison with other animals that were treated with bio-Cu NPs; these results make $\mathrm{ZnO}$ NPs a promising candidate alternative for biomedical applications. Moreover, Umar et al. demonstrated that ZnO NPs exhibit remarkable cytotoxic effects and ability to stimulate blebs on plasma membrane of breast cancer cell lines, which reinforces their apoptotic mechanism of action [75]. Membrane blebs and a decline in cell viability that were noticed in the treated cells might be caused by ROS, metal ions $\left(\mathrm{Zn}^{+2}\right)$, and other molecules that were released in the medium by ZnO NPs. Furthermore, Siddiqi et al. stated that zinc oxide nanoparticles can be used for treating wounds, ulcers, and several microbial infections and also as a drug carrier in cancer treatment [76]. Accordingly, it is known to be a safe antibacterial agent that may substitute for antibiotics. Also, application of zinc oxide nanoparticles in various fields of science, medicine, and technology suggests that it is an essential substance for humans and animals.

Overall, the usage of medicinal plant extracts as possible reducing and stabilization agents to synthesize $\mathrm{ZnO}$ nanoparticles provides several advantages over conventional physical and highly toxic chemical techniques [77].

\section{Conclusion}

This investigation described a green process for the formation of $\mathrm{ZnO}$ NPs by using Mentha longifolia $\mathrm{L}$. which is an easy and eco-friendly procedure in the field of applied nanotechnology. In addition, as the ZnO NPs showed a scolicidal activity due to their small size, they could be employed for pharmaceutical purposes. Dose- and time-dependent mortality of the treated protoscolices was investigated. At highest concentration, $400 \mathrm{ppm}$, the percentage of mortality reached $100 \%$; all protoscoleces absorbed the eosin stain and were stained red which points to their death within $2.5 \mathrm{~h}$. The protoscoleces of the control group remained viable and appeared to be colorless. The current investigation with its encouraging results is a good beginning for additional research on the $\mathrm{ZnO}$ NPs against parasites. Nevertheless, additional investigations are needed on the cellular and molecular mechanism. The extracellular synthesis of $\mathrm{ZnO}$ NPs could be extremely appreciated from the viewpoint of large-scale processes and using different types and sizes of NPs in in vivo animal model and for diverse uses. Further studies are required to investigate the effect of $\mathrm{ZnO}$ NPs in vivo within the animal model and for different periods.

Acknowledgements The authors would like to acknowledge Soran University and Ulster University for their support with data analysis.
Author contribution All authors contributed equally to the design and implementation of the research, to the analysis of the results, and to the writing of the manuscript.

Availability of data and material The authors confirm that the data supporting the findings of this study are available within the article.

Code availability Not applicable.

\section{Declarations}

Ethics approval Access to the infected hepatic sheep cells was granted by the Veterinary Medicine Department in Soran city, Kurdistan.

Consent to participate Not applicable.

Consent for publication Not applicable.

Conflict of interest The authors declare no competing interests.

Open Access This article is licensed under a Creative Commons Attribution 4.0 International License, which permits use, sharing, adaptation, distribution and reproduction in any medium or format, as long as you give appropriate credit to the original author(s) and the source, provide a link to the Creative Commons licence, and indicate if changes were made. The images or other third party material in this article are included in the article's Creative Commons licence, unless indicated otherwise in a credit line to the material. If material is not included in the article's Creative Commons licence and your intended use is not permitted by statutory regulation or exceeds the permitted use, you will need to obtain permission directly from the copyright holder. To view a copy of this licence, visit http://creativecommons.org/licenses/by/4.0/.

\section{References}

1. J. Jiang, J. Pi, J. Cai, The Advancing of Zinc Oxide Nanoparticles for Biomedical Applications. Bioinorg Chem Appl 5, 1062562 (2018). https://doi.org/10.1155/2018/1062562

2. Y. Zhang, T.R. Nayak, H. Hong, W. Cai, Biomedical applications of zinc oxide nanomaterials. Curr. Mol. Med. 13(10), 1633-1645 (2013)

3. D. Chen, S. Ai, Z. Liang, F. Wei, Preparation and photocatalytic properties of zinc oxide nanoparticles by microwave-assisted ball milling. Ceram. Int. 42(2), 3692-3696 (2016)

4. E. Darvishi, D. Kahrizi, E. Arkan, Comparison of different properties of zinc oxide nanoparticles synthesized by the green (using Juglans regia L. leaf extract) and chemical methods. J. Mol. Liquids 286, 110831 (2019)

5. A.A. Barzinjy, H.H. Azeez, Green synthesis and characterization of zinc oxide nanoparticles using Eucalyptus globulus Labill. leaf extract and zinc nitrate hexahydrate salt. SN Appl. Sci. 2(5), 1-14 (2020)

6. H. Mirzaei, M. Darroudi, Zinc oxide nanoparticles: biological synthesis and biomedical applications. Ceram. Int. 43(1), 907-914 (2017)

7. J. Singh, T. Dutta, K.-H. Kim, M. Rawat, P. Samddar, P. Kumar, 'Green' synthesis of metals and their oxide nanoparticles: applications for environmental remediation. J. Nanobiotechnol. 16(1), 84 (2018) 
8. M.A. Albrecht, C.W. Evans, C.L. Raston, Green chemistry and the health implications of nanoparticles. Green Chem. 8(5), 417-432 (2006)

9. N. Pantidos, L.E. Horsfall, Biological synthesis of metallic nanoparticles by bacteria, fungi and plants. J. Nanomed. Nanotechnol. 5(5), 1 (2014)

10. M. Ovais, A.T. Khalil, N.U. Islam, I. Ahmad, M. Ayaz, M. Saravanan, Z.K. Shinwari, S. Mukherjee, Role of plant phytochemicals and microbial enzymes in biosynthesis of metallic nanoparticles. Appl. Microbiol. Biotechnol. 102(16), 6799-6814 (2018)

11. S. Raj, S.C. Mali, R. Trivedi, Green synthesis and characterization of silver nanoparticles using Enicostemma axillare (Lam.) leaf extract. Biochem. Biophys. Res. Commun. 503(4), 2814-2819 (2018)

12. A.A. Barzinjy, S.M. Hamad, A.F. Abdulrahman, S.J. Biro, A.A. Ghafor, Biosynthesis, characterization and mechanism of formation of $\mathrm{ZnO}$ nanoparticles using Petroselinum crispum leaf extract. Curr. Org. Synth. 17(7), 558-566 (2020)

13. S. Ghaderi, B. Ramesh, A.M. Seifalian, Fluorescence nanoparticles "quantum dots" as drug delivery system and their toxicity: a review. J. Drug Target. 19(7), 475-486 (2011)

14. M. Nasrollahzadeh, M. Sajjadi, M. Maham, S.M. Sajadi, A.A. Barzinjy, Biosynthesis of the palladium/sodium borosilicate nanocomposite using Euphorbia milii extract and evaluation of its catalytic activity in the reduction of chromium (VI), nitro compounds and organic dyes. Mater. Res. Bull. 102, 24-35 (2018)

15. S.M. Sajadi, K. Kolo, S.M. Hamad, S.A. Mahmud, A.A. Barzinjy, S.M. Hussein, Green synthesis of the Ag/bentonite nanocomposite using Euphorbia larica extract: a reusable catalyst for efficient reduction of nitro compounds and organic dyes. ChemistrySelect 3(43), 12274-12280 (2018)

16. A.A. Barzinjy, D.A. Abdul, F.H. Hussain, S.M. Hamad, Green synthesis of the magnetite ( $\mathrm{Fe} 3 \mathrm{O} 4)$ nanoparticle using Rhus coriaria extract: a reusable catalyst for efficient synthesis of some new 2-naphthol bis-Betti bases. Inorg. Nano-Metal Chem. 50, 1-10 (2020)

17. A.A. Barzinjy, S.M. Hamad, M.M. Esmaeel, S.K. Aydın, F.H.S. Hussain, Biosynthesis and characterisation of zinc oxide nanoparticles from Punica granatum (pomegranate) juice extract and its application in thin films preparation by spin-coating method. Micro Nano Lett. 15(6), 415-420 (2020)

18. A.A Barzinjy, S.M. Hamad, S. Aydın, et al. Green and ecofriendly synthesis of Nickel oxide nanoparticles and its photocatalytic activity for methyl orange degradation. J Mater Sci: Mater Electron 31, 11303-11316 (2020). https://doi.org/10.1007/ s10854-020-03679-y

19. H.H. Azeez, A.A. Barzinjya, Biosynthesis zinc oxide nanoparticles using Apium graveolens L. leaf extract and its use in removing the organic pollutants in water. Desalin. Water Treat. 190, 179-192 (2020)

20. H. Shi, Y. Lei, B. Wang, Z. Wang et al., Protoscolicidal effects of chenodeoxycholic acid on protoscoleces Echinococcus granulosus. Exp. Parasitol. 167, 76-82 (2016). https://doi.org/10.1016/j. exppara.2016.05.004

21. G. Adas, S. Arikan, O. Kemik, A. Oner, N. Sahip, O. Karatepe, Use of albendazole sulfoxide, albendazole sulfone, and combined solutions as scolicidal agents on hydatid cysts (in vitro study). World J Gastroenterol. 15(1), 112-116 (2009). https://doi.org/10. 3748/wjg. 15.112

22. A. Albi, F. Baudin, M. Matmar, D. Archambeau, Y. Ozier, Severe hypernatremia after hypertonic saline irrigation of hydatid cysts. Anesth Analg. 95(6), 1806-8, table of contens (2002). https://doi. org/10.1097/00000539-200212000-00062

23. P.S. Craig, D.P. McManus, M.W. Lightowlers, J.A. Chabalgoity, H.H. Garcia, C.M. Gavidia, R.H. Gilman, A.E. Gonzalez, M.
Lorca, C. Naquira, Prevention and control of cystic echinococcosis. Lancet. Infect. Dis 7(6), 385-394 (2007)

24. J. Eckert, F. Conraths, K. Tackmann, Echinococcosis: an emerging or re-emerging zoonosis? Int. J. Parasitol. 30(12-13), 1283-1294 (2000)

25. A.M. da Silva, Human echinococcosis: a neglected disease. Gastroenterol Res Pract. 2010;2010:583297. https://doi.org/10.1155/ 2010/583297

26. A.L. Molan, L.A.-A. Saida, Echinococcosis in Iraq: prevalence of Echinococcus granulosus in stray dogs in Arbil province. Jpn. J. Med. Sci. Biol. 42(4), 137-141 (1989)

27. S.M. Sadjjadi, Present situation of echinococcosis in the Middle East and Arabic North Africa. Parasitol. Int. 55, S197-S202 (2006)

28. U. Koziol, K. Brehm, Recent advances in Echinococcus genomics and stem cell research. Vet. Parasitol. 213(3-4), 92-102 (2015)

29. R.W. Ammann, J. Eckert, Cestodes: Echinococcus. Gastroenterol. Clin. 25(3), 655-689 (1996)

30. J. Scott, J. Stefaniak, Z. Pawlowski, D. McManus, Molecular genetic analysis of human cystic hydatid cases from Poland: identification of a new genotypic group (G9) of Echinococcus granulosus. Parasitology 114(1), 37-43 (1997)

31. E. Brunetti, P. Kern, D.A. Vuitton, Expert consensus for the diagnosis and treatment of cystic and alveolar echinococcosis in humans. Acta Trop. 114(1), 1-16 (2010)

32. T. Junghanss, A.M. Da Silva, J. Horton, P.L. Chiodini, E. Brunetti, Clinical management of cystic echinococcosis: state of the art, problems, and perspectives. Am. J. Trop. Med. Hyg. 79(3), 301-311 (2008)

33. B. Evrard, P. Chiap, P. DeTullio, F. Ghalmi, G. Piel, T. Van Hees, J. Crommen, B. Losson, L. Delattre, Oral bioavailability in sheep of albendazole from a suspension and from a solution containing hydroxypropyl- $\beta$-cyclodextrin. J. Control. Release 85(1-3), 45-50 (2002)

34. B.H. Shnawa, Advances in the use of nanoparticles as anticystic echinococcosis agents: a review article. J. Pharm. Res. Int. 24, 1-14 (2018)

35. M. Moazeni, S.V. Hosseini, M.H. Al-Qanbar, A.M. Alavi, H. Khazraei, In vitro evaluation of the protoscolicidal effect of Eucalyptus globulus essential oil on protoscolices of hydatid cyst compared with hypertonic saline, povidone iodine and silver nitrate. J Visc Surg. 156(4), 291-295 (2019). https://doi.org/ 10.1016/j.jviscsurg.2019.01.002

36. T.A. Salih, K.T. Hassan, S.R. Majeed et al., In vitro scolicidal activity of synthesised silver nanoparticles from aqueous plant extract against Echinococcus granulosus. Biotechnol. Rep. 28, e00545 (2020). https://doi.org/10.1016/j.btre.2020.e00545

37. H. Barabadi, S. Honary, M. Ali Mohammadi, E. Ahmadpour, M.T. Rahimi, A. Alizadeh, F. Naghibi, M. Saravanan, Green chemical synthesis of gold nanoparticles by using Penicillium aculeatum and their scolicidal activity against hydatid cyst protoscolices of Echinococcus granulosus. Environ Sci Pollut Res Int. 24(6), 5800-5810 (2017). https://doi.org/10.1007/ s11356-016-8291-8

38. T. Chitradevi, A.J. Lenus, J.N. Victor, Structure, morphology and luminescence properties of sol-gel method synthesized pure and $\mathrm{Ag}$-doped $\mathrm{ZnO}$ nanoparticles. Mater. Res. Express 7, 015011 (2020)

39. S. Pai, H. Sridevi, T. Varadavenkatesan, R. Vinayagam, R. Selvaraj, Photocatalytic zinc oxide nanoparticles synthesis using Peltophorum pterocarpum leaf extract and their characterization. Optik 185, 248-255 (2019)

40. T. Safawo, B. Sandeep, S. Pola, A. Tadesse, Synthesis and characterization of zinc oxide nanoparticles using tuber extract of anchote (Coccinia abyssinica (Lam.) Cong.) for antimicrobial and antioxidant activity assessment. OpenNano 3, 56-63 (2018) 
41. M. Ramesh, M. Anbuvannan, G. Viruthagiri, Green synthesis of $\mathrm{ZnO}$ nanoparticles using Solanum nigrum leaf extract and their antibacterial activity. Spectrochim. Acta Part A Mol. Biomol. Spectrosc. 136, 864-870 (2015)

42. B. Siripireddy, B.K. Mandal, Facile green synthesis of zinc oxide nanoparticles by Eucalyptus globulus and their photocatalytic and antioxidant activity. Adv. Powder Technol. 28(3), 785-797 (2017)

43. A. Samy, A.E. El-Sherbiny, A. Menazea, Green synthesis of high impact zinc oxide nanoparticles. Egypt. J. Chem. 62(The First International Conference on Molecular Modeling and Spectroscopy 19-22 February, 2019), 29-37 (2019)

44. Y. Wang, X. Zhao, L. Duan, F. Wang, H. Niu, W. Guo, A. Ali, Structure, luminescence and photocatalytic activity of Mg-doped $\mathrm{ZnO}$ nanoparticles prepared by auto combustion method. Mater. Sci. Semicond. Process. 29, 372-379 (2015)

45. D. Dash, N. Panda, D. Sahu, Photoluminescence and photocatalytic properties of europium doped $\mathrm{ZnO}$ nanoparticles. Appl. Surf. Sci. 494, 666-674 (2019)

46. S. Yedurkar, C. Maurya, P. Mahanwar, Biosynthesis of zinc oxide nanoparticles using Ixora coccinea leaf extract-a green approach. Open J. Synth. Theory Appl. 5(1), 1-14 (2016)

47. P.R. Griffiths, J.A. De Haseth, Fourier Transform Infrared Spectrometry, vol. 171 (John Wiley \& Sons, 2007)

48. F.A. Al-Bayati, Isolation and identification of antimicrobial compound from Mentha longifolia L. leaves grown wild in Iraq. Ann. Clin. Microbiol. Antimicrob. 8(1), 20 (2009)

49. N. Jayarambabu, B.S. Kumari, K.V. Rao, Y. Prabhu, Beneficial role of zinc oxide nanoparticles on green crop production. Int. J. Multidiscip. Adv. Res. Trends 2, 273-282 (2015)

50. S. Zandi, P. Kameli, H. Salamati, H. Ahmadvand, M. Hakimi, Microstructure and optical properties of $\mathrm{ZnO}$ nanoparticles prepared by a simple method. Physica B 406(17), 3215-3218 (2011)

51. V. Srivastava, D. Gusain, Y.C. Sharma, Synthesis, characterization and application of zinc oxide nanoparticles (n-ZnO). Ceram. Int. 39(8), 9803-9808 (2013)

52. H. Kumar, R. Rani, Structural and optical characterization of $\mathrm{ZnO}$ nanoparticles synthesized by microemulsion route. Int. Lett. Chem., Phys. Astron. 14, 26-36 (2013)

53. R. Norouzi, M. Hejazy, A. Ataei, Scolicidal activity of zinc oxide nanoparticles against hydatid cyst protoscolices in vitro. Nanomed. Res. J. 4(1), 23-28 (2019)

54. R. Norouzi, A. Ataei, M. Hejazy, A. Noreddin, M.E. El Zowalaty, Scolicidal effects of nanoparticles against hydatid cyst protoscolices in vitro. Int. J. Nanomed. 15, 1095 (2020)

55. A.A.-J. Ibrahim, Scolicidal activity of zirconium oxide $(\mathrm{ZrO})$ nanoparticles against protoscolices of hydatid cysts. Indian J. Forensic Med. Toxicol. 14(2), 409 (2020)

56. S. Baker, D. Rakshith, K.S. Kavitha et al., Plants: emerging as nanofactories towards facile route in synthesis of nanoparticles. BioImpacts 3(3), 111-117 (2013)

57. J.K. Patra, K.-H. Baek, Green nanobiotechnology: factors affecting synthesis and characterization techniques. J. Nanomater. 2014, 417305 (2014). https://doi.org/10.1155/2014/417305

58. A. Ksia, M.B. Fredj, A. Zouaoui, N. Kechiche, S. Belhassen, S. Mosbahi, S.B. Youssef, S. Sfar, R. Lamiri, L. Sahnoun, Capitonnage seems better in childhood pulmonary hydatid cyst surgery. J. Pediatr. Surg. 55(4), 752-755 (2020)

59. L. Roncati, G. Barbolini, A.T. Scacchetti, S. Busani, A. Maiorana, Unexpected death: anaphylactic intraoperative death due to Thymoglobulin carbohydrate excipient. Forensic Sci. Int. 228(1-3), e28-e32 (2013)

60. B. Sumanth, T.R. Lakshmeesha, M.A. Ansari, M.A. Alzohairy, A.C. Udayashankar, B. Shobha, S.R. Niranjana, C. Srinivas, A. Almatroudi, Mycogenic synthesis of extracellular zinc oxide nanoparticles from Xylaria acuta and its nanoantibiotic potential. Int. J. Nanomed. 15, 8519 (2020)
61. Y. Li, J. Niu, E. Shang, J.C. Crittenden, Influence of dissolved organic matter on photogenerated reactive oxygen species and metal-oxide nanoparticle toxicity. Water Res. 98, 9-18 (2016)

62. Y.N. Slavin, J. Asnis, U.O. Häfeli, H. Bach, Metal nanoparticles: understanding the mechanisms behind antibacterial activity. J. Nanobiotechnol. 15(1), 1-20 (2017)

63. A. Sirelkhatim, S. Mahmud, A. Seeni, N.H.M. Kaus, L.C. Ann, S.K.M. Bakhori, H. Hasan, D. Mohamad, Review on zinc oxide nanoparticles: antibacterial activity and toxicity mechanism. Nano-Micro Lett. 7(3), 219-242 (2015)

64. B. Pelaz, C. Alexiou, R.A. Alvarez-Puebla, F. Alves, A.M. Andrews, S. Ashraf, L.P. Balogh, L. Ballerini, A. Bestetti, C. Brendel, Diverse Applications of Nanomedicine (ACS Publications, Washington, DC, 2017)

65. K. Qi, B. Cheng, J. Yu, W. Ho, Review on the improvement of the photocatalytic and antibacterial activities of ZnO. J. Alloy. Compd. 727, 792-820 (2017)

66. I. Kim, K. Viswanathan, G. Kasi, K. Sadeghi, S. Thanakkasaranee, J. Seo, Poly (lactic acid)/ZnO bionanocomposite films with positively charged $\mathrm{ZnO}$ as potential antimicrobial food packaging materials. Polymers 11(9), 1427 (2019)

67. S.T. Ishida, Anti-bacterial vaccine activities of bacteriolyses by $\mathrm{Zn}$ 2-induced peptidoglycan autolysins and zinc-, ZnONPs-dependent lyses in bacterial cell walls. Int. J. Res. Stud. Med. Health Sci. 4(10), 2-13 (2019)

68. B.R. Giri, B. Roy, Resveratrol induced structural and biochemical alterations in the tegument of Raillietina echinobothrida. Parasitol. Int. 63(2), 432-437 (2014)

69. S.M. Mousavi, A. Afgar, M.A. Mohammadi, S. Mortezaei, A. Faridi, B. Sadeghi, M. Fasihi Harandi, Biological and morphological consequences of dsRNA-induced suppression of tetraspanin mRNA in developmental stages of Echinococcus granulosus. Parasit. Vectors 13, 1-10 (2020)

70. J.F. Kerr, A.H. Wyllie, A.R. Currie, Apoptosis: a basic biological phenomenon with wide ranging implications in tissue kinetics. Br. J. Cancer 26(4), 239 (1972)

71. J. Li, G. Tang, W. Qin, R. Yang, R. Ma, B. Ma, J. Wei, H. Lv, Y. Jiang, Toxic effects of arsenic trioxide on Echinococcus granulosus protoscoleces through ROS production, and $\mathrm{Ca} 2+-\mathrm{ER}$ stressdependent apoptosis. Acta Biochim. Biophys. Sin. 50(6), 579-585 (2018)

72. H. Mahmoudvand, M.F. Harandi, M. Shakibaie, M.R. Aflatoonian, N. ZiaAli, M.S. Makki, S. Jahanbakhsh, Scolicidal effects of biogenic selenium nanoparticles against protoscolices of hydatid cysts. Int. J. Surg. 12(5), 399-403 (2014)

73. M.T. Rahimi, E. Ahmadpour, B.R. Esboei, A. Spotin, M.H.K. Koshki, A. Alizadeh, S. Honary, H. Barabadi, M.A. Mohammadi, Scolicidal activity of biosynthesized silver nanoparticles against Echinococcus granulosus protoscolices. Int. J. Surg. 19, 128-133 (2015)

74. C. Ashajyothi, H.K. Handral, A comparative in vivo scrutiny of biosynthesized copper and zinc oxide nanoparticles by intraperitoneal and intravenous administration routes in rats. Nanoscale Res. Lett. 13(1), 93 (2018)

75. H. Umar, D. Kavaz, N. Rizaner, Biosynthesis of zinc oxide nanoparticles using Albizia lebbeck stem bark, and evaluation of its antimicrobial, antioxidant, and cytotoxic activities on human breast cancer cell lines. Int. J. Nanomed. 14, 87 (2019)

76. K.S. Siddiqi, A. ur Rahman, A. Husen, Properties of zinc oxide nanoparticles and their activity against microbes. Nanoscale Res. Lett. 13(1), 1-13 (2018)

77. A.K. Mittal, Y. Chisti, U.C. Banerjee, Synthesis of metallic nanoparticles using plant extracts. Biotechnol. Adv. 31, 346-356 (2013)

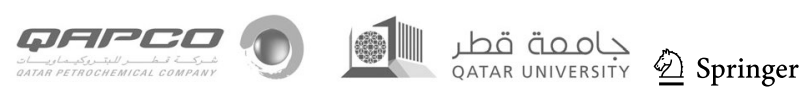

